\title{
A NEW HYBRID FUZZY PSI-PIPRECIA-COCOSO MCDM BASED APPROACH TO SOLVING THE TRANSPORTATION COMPANY SELECTION PROBLEM
}

\author{
Alptekin ULUTAŞ ${ }^{1}$, Gabrijela POPOVIC ${ }^{2}$, Pavle RADANOV ${ }^{2}$, \\ Dragisa STANUJKIC ${ }^{3}$, Darjan KARABASEVIC ${ }^{2^{*}}$ \\ ${ }^{1}$ Department of International Trade and Logistics, Faculty of Economics and Administrative Sciences, \\ Sivas Cumhuriyet University, Sivas, Turkey \\ ${ }^{2}$ Faculty of Applied Management, Economics and Finance, University Business Academy in Novi Sad, \\ Belgrade, Serbia \\ ${ }^{3}$ Technical Faculty in Bor, University of Belgrade, Bor, Serbia
}

Received 10 November 2020; accepted 11 April 2021; first published online 07 July 2021

\begin{abstract}
Nowadays, customers are not only interested in the quality of products, but they also want to have these products in a timely manner. The managers of an organization are faced with two problems when the distribution of products is in question, namely: (1) customers are usually geographically dispersed and (2) transportation should be performed in a cost-effective way. Although managers may have a significant experience and formal knowledge, decisions connected with the selection of an appropriate transportation company may very often be biased. For the purpose of avoiding making the inadequate decisions that might harm the operation of the organization, the application of a hybrid MCDM model is proposed in this paper. The proposed model consists of three fuzzy MCDM methods, including: the PIPRECIA, the PSI, and the CoCoSo methods. The fuzzy-PIPRECIA method is used to achieve the subjective weights of criteria, whereas the fuzzy-PSI method is used to obtain the objective weights of criteria. Fuzzy-CoCoSo is utilized to rank alternative transportation companies according to their performances. The possibilities of the proposed hybrid model are tested on a real case study pointed at the selection of an appropriate company for the transportation of ready-garments to retailers in Turkey.
\end{abstract}

Keywords: MCDM, fuzzy PIPRECIA method, fuzzy PSI method, fuzzy CoCoSo method, hybrid model, transportation company selection.

JEL Classification: D81, C02, C44, L91.

\section{Introduction}

The distribution of products to customers is an important stage which determines whether an organization will achieve an excellent business performance or not. In the environment of the modern economy, customers do not only require a high product quality, but they also require

${ }^{*}$ Corresponding author. E-mail: darjan.karabasevic@mef.edu.rs

Copyright (c) 2021 The Author(s). Published by Vilnius Gediminas Technical University

This is an Open Access article distributed under the terms of the Creative Commons Attribution License (http://creativecommons. org/licenses/by/4.0/), which permits unrestricted use, distribution, and reproduction in any medium, provided the original author and source are credited. 
a fast, adjustable and reliable delivery of those products (Christopher, 2012). In that manner, the organization will gain its customers' trust not only because of the product quality, but also for the reason of a timely and responsible delivery. The shipping issue is complicated by the fact that the customers of an organization are usually geographically scattered, so logistic managers should carefully plan the transportation of particular products (Mota et al., 2015).

A challenging business environment imposes an obligation upon the organization to deliver its products to its customers in a cost-effective manner, without compromising the transportation budget (Kulak \& Kahraman, 2005). With that requirement in mind, logistic managers' main concern is the issue of the selection of the transportation company that will fulfil the set preconditions. Although managers are aware of the organization's and productrelated transportation requirements, they might fail to make a choice consistent with predicted specifications, because every choice is more or less biased (Tokar, 2010). Different managers might make different decisions under the same conditions, because they would prioritize different types of criteria and select transportation according to them. One way to overcome a problem of this kind and make more reliable decisions is to apply MultipleCriteria Decision-Making (MCDM) methods.

The MCDM methods that belong to the operation research field have become very popular in recent years (Jaukovic Jocic et al., 2020). These methods have been used to facilitate the decision-making process in many business fields and to solve various real-world problems (Torkayesh et al., 2021; Bagočius et al., 2014; Turskis et al., 2012). Some of the best-known MCDM methods are certainly the following: the Analytic Hierarchy Process - AHP (Saaty, 1980), Simple Additive Weight - SAW (Churchman \& Ackoff, 1954), the Technique for Order of Preference by Similarity to Ideal Solution - TOPSIS (Hwang \& Yoon, 1981), the Preference Ranking Organization METHod for Enrichment of Evaluations - PROMETEE (Brans \& Vincke, 1985), the ELimination Et Choix Traduisant la REalité method - ELECTRE (Roy, 1991) and VIseKriterijumska Optimizacija I Kompromisno Resenje - VIKOR (Opricovic, 1998). Beside these, scholars have also introduced new and improved multicriteria techniques suitable for the execution of the most complex issues. Some of the comprehensive overviews of the proposed MCDM methods and their applications could be found in the papers written by the following authors: Zavadskas et al. (2014), and Ilgin et al. (2015). Furthermore, in order to avoid biased decisions and choices, researchers have introduced extensions of many MCDM methods by involving fuzzy, grey or neutrosophic numbers. Therefore, the uncertainty of the environment where the decision-making process is conducted is acknowledged and involved in the decision-making process that leads to the promulgation of more reliable decisions. In some papers, such as those authored by Zavadskas et al. (2016), Afful-Dadzie et al. (2017), and Liao et al. (2018) a good summary of the extensions of those methods and their utilization is given.

For the purpose of obtaining a proper decision on the selection of an adequate transportation company, a hybrid model based on the PIvot Pairwise RElative Criteria Importance Assessment - PIPRECIA, introduced by Stanujkic et al. (2017a), the Preference Selection Index - PSI, proposed by Maniya and Bhatt (2010), and the Combined Compromise Solution - CoCoSo, developed by Yazdani et al. (2018) in a fuzzy environment, is proposed. The significance of the considered evaluation criteria is determined by the application of 
the fuzzy PIPRECIA and fuzzy PSI methods. By combining the subjectively- (PIPRECIA) and objectively- (PSI) oriented methods in a fuzzy environment, the obtained weights will be more reliable; the reason for that is twofold: (1) subjective, as well as objective, results in order to reflect reality to the greatest possible extent; and (2) by introducing fuzzy sets, the ambiguousness of the decision environment is appreciated. The final ranking order of the alternative transportations companies is obtained by applying the fuzzy CoCoSo method, which has recently been proposed and whose possibilities have not been fully examined yet. The applicability of the proposed hybrid model is tested on a real case study pointed at the selection of the company for the transportation of ready-garments from a textile workshop to retailers in Turkey. The five managers who work in the mentioned workshop are engaged in the decision-making process.

In order to present the developed hybrid model and its potential, the remainder of the paper is organized into five sections. In Section 1, a comprehensive review of the current state and findings in the considered field are presented. Section 2 contains the presentation of the methodology divided into three subsections: Fuzzy PIPRECIA, Fuzzy PSI and Fuzzy CoCoSo. A case study is introduced in Section 3, which is followed by the section presenting the conclusion and suggestions for future research.

\section{Literature review}

The value of an organization does not only depend only on the quality of the offered products, but it also depends on an appropriate and timely delivery provided by the organization. A certain product will have a value for the customer only when they can consume it in a particular place and at a particular time. In order to achieve this goal, organizations should carefully organize product delivery, i.e. they should pay appropriate attention to the question of logistics (Ballou, 1997). An adequate selection of the transportation mode and a transportation company will not only add value to the organization's performance with respect to its quality, but it will also contribute to a reduction in costs. In the conditions of the modern economy, organizations are faced with fierce competition in all areas, and only thoroughly prepared actions will enable them to achieve success in their business doing (Sandberg, 2013).

Making decisions on the selection of adequate transportation modes and contracting the most suitable transportation companies requires the realization of all the aspects important for such a decision. In order to obtain an appropriate solution, many scholars have proposed the application of MCDM methods as a convenient decision aid. Kulak and Kahraman (2005) select an appropriate transportation company by applying the fuzzy multi-criteria axiomatic design and the AHP method. Wang and Chen (2011) further examined this case and concluded that the fuzzy linguistic preference relations (fuzzy LinPreRa) proposed by Wang and Chen (2008) are more suitable to apply in the case of the selection of a transportation company than consistent fuzzy preference relations (Herrera-Viedma et al., 2004). Đalić et al. (2020) have proposed a novel integrated fuzzy PIPRECIA - interval rough SAW model for green supplier selection. An MCDM approach based on the fuzzy AHP method is also proposed as a convenient tool which could solve the transportation problem and enable the minimization 
of the logistics cost, while customer satisfaction is increased (He et al., 2012). Besides, the fuzzy VIKOR method is recognized as a suitable technique for the selection of a company for hazardous waste transportation (Kabir, 2015). Apart from that, researchers often studied the problem of the selection of a transportation mode and possibilities of applying MCDM methods in the considered area (Kundu et al., 2014; Zheng, 2015; Samanta \& Jana, 2019). For the purpose of this paper, an integrated model for the selection of a transportation company based on the PIPRECIA, PSI and CoCoSo methods in a fuzzy environment is introduced.

Until now, authors have used different approaches for determining the criteria significance (Zemlickienė \& Turskis, 2020; Turskis et al., 2019a, 2019b; Keshavarz-Ghorabaee et al., 2018; Stanujkic et al., 2017b; Erdogan et al., 2017; Razavi Hajiagha et al., 2015). The PIPRECIA method (Stanujkic et al., 2017a) is a recently introduced method quite suitable for determining the significance of criteria in a group decision-making environment. This method originates from the SWARA method, proposed by Keršuliene et al. (2010). The authors of the PIPRECIA method discovered the main weakness of the SWARA method, which reflects through its inappropriateness for application in the case of group decision-making. Namely, the procedure of the given method complicates the obtaining of the final results when there are more decision-makers involved in the decision-making process. For example, Popović et al. (2018) applied the SWARA method for prioritization of the factors regarding the tourism development of the Sokobanja Spa in the group decision environment. Besides its simply numerical procedure, the pre-sorting of the considered factors complicated obtaining the overall results from all involved decision-makers. In the PIPRECIA method, this problem is overcome by omitting the pre-sorting of evaluation criteria, which directly facilitates the determination of the final criteria weights in the case of group decision-making. Later, Stević et al. (2018) extended the PIPRECIA method by introducing fuzzy logic, in which way these authors better incorporated the vagueness and ambiguity of the environment in decisionmaking. Until now, authors have used the PIPRECIA method to facilitate decision-making in diverse areas, such as: hotel and tourism industry (Stanujkic et al., 2018; Popovic et al., 2019; Karabašević et al., 2019), information technology (Stević et al., 2018), and customer satisfaction (Stanujkic et al., 2019).

As previously said, the PSI method is the method introduced by Maniya and Bhatt in 2010, which represents a very vigorous decision-making tool. The main characteristic of this method is that there is no need for giving relative significance between criteria. In fact, criteria significance is determined by applying a statistics-based approach. In that manner, decision-makers obtain an objectively-oriented more reliable criteria significance. Furthermore, the PSI method is very suitable to apply in the cases when there is a conflict regarding the determination of criteria significance (Vahdani et al., 2014). So far, it has been used to facilitate decision-making in the following areas: production (Maniya \& Bhatt, 2011; Attri, \& Grover, 2015), renewable energy (Chauhan et al., 2016), the vehicle selection problem (Sawant et al., 2011), job scheduling (Paul et al., 2016), sustainable mining (Borujeni \& Gitinavard, 2017) and recycling (Mohagheghi et al., 2016).

CoCoSo (Yazdani et al., 2018) is also a relatively new method which relies on the SAW method and the exponentially weighted product model. The core of this method reflects through a combination of compromise perspectives, in which way the final solution recon- 
ciliates predicted, however conflicting criteria. Beside the fact that this method has recently been introduced, it has proven to be applicable in the areas such as supplier selection (Zolfani et al., 2019) and the evaluation of electric vehicles (Biswas et al., 2019). Additionally, authors have already proposed the adequate extensions of the CoCoSo method. For example, Yazdani et al. (2019) used grey CoCoSo (CoCoSo-G) to solve the problem of supplier selection, while Peng et al. (2019) proposed the application of the Pythagorean fuzzy MCDM model, which relies on CoCoSo and CRITIC with a score function. Wen et al. (2019a) suggested hesitant fuzzy linguistic CoCoSo as a suitable tool for facilitating the decision-making process. Neutrosophic CoCoSo presents itself as a good technique for the selection of a waste disposal site (Karaşan \& Bolturk, 2019). Mainly aimed at reducing the costs of stock management, Erceg et al. (2019) propose the model that involves the Interval Rough CoCoSo method. Wen et al. (2019b) proposed the probabilistic linguistic SWARA-CoCoSo model as a clinical decisionmaking support. In the field of logistics, scholars have applied the extended CoCoSo method with hesitant fuzzy linguistic numbers as a tool convenient for making proper decisions and choices (Wen et al., 2019c). The main reason for the application of this method for the selection of the suitable transportation company relies exactly on the fact that it enables the finding of such a solution that compromises all of the considered criteria. This is very important because in the business it is very important to take into account all relevant influential factors in order to discover the best possible solution.

For the purpose of this paper, a hybrid model relying on the fuzzy PIPRECIA and PSI methods for the determination of the criteria weights and the fuzzy CoCoSo method for the final ranking of the considered transportation companies is proposed. The main reason for choosing the fuzzy PIPRECIA and PSI methods for defining the criteria weights is, firstly, because of its easiness of use in the group decision-making environment. Besides, by applying the subjective (PIPRECIA) and objective (PSI) approaches, the obtained results are more reliable and realistic. The results obtained by applying the CoCoSo method are a kind of compromise solution reconsolidating different expectations from the criteria. The extension with fuzzy numbers is proposed in order to better express and acknowledge the ambiguity and vagueness of the decision-making environment and the stance of the involved decisionmakers. All of these methods have recently been introduced and their potentials have not been fully examined yet, not in an individual use and not in a collective use, either.

\section{The proposed hybrid model}

In this section, an overview of the MCDM methods used to form the hybrid MCDM model is presented.

\subsection{Fuzzy PIPRECIA}

The fuzzy PIPRECIA method enables criteria to be assessed without their prior sorting, which is an advantage of the fuzzy PIPRECIA method over the fuzzy SWARA method (Stević et al., 2018). The steps of the fuzzy PIPRECIA method are explained as follows: (Stević et al., 2018). 
Step 1-1: The decision-maker $(\mathrm{DM}(\mathrm{s}))$ sorts the criteria according to their expected priorities.

Step 1-2: Starting from the second criterion, each DM individually assesses the pre-sorted criteria so as to identify the relative importance of the criteria $\left(\widetilde{e_{j}^{r}}\right)$.

$$
\widetilde{e_{j}^{r}}=\left\{\begin{array}{lll}
>\tilde{1} & \text { if } & C_{j}>C_{j-1} \\
=\tilde{1} & \text { if } & C_{j}=C_{j-1} \\
<\tilde{1} & \text { if } & C_{j}<C_{j-1}
\end{array} .\right.
$$

In Eq. (9), $\widetilde{e_{j}^{r}}$ is the evaluation of the $j$ th criterion by the DM $r$. When assigning $\widetilde{e_{j}^{r}}$, DMs use the linguistic variables displayed in Table 1 and Table 2. To achieve $\widetilde{e_{j}}\left(e_{j}^{l}, e_{j}^{m}, e_{j}^{u}\right)$, all $\widetilde{e_{j}^{r}}$ values are aggregated by using the geometric mean.

Table 1. The linguistic variables for the evaluation of the criteria (Scale 1-2) (Stević et al., 2018)

\begin{tabular}{|l|c|}
\hline \multicolumn{1}{|c|}{ Linguistic variables } & Fuzzy numbers \\
\hline Absolutely more significant & $(1.600,1.900,1.950)$ \\
\hline Dominantly more significant & $(1.500,1.750,1.800)$ \\
\hline Much more significant & $(1.400,1.600,1.650)$ \\
\hline More significant & $(1.300,1.450,1.500)$ \\
\hline Moderately more significant & $(1.200,1.300,1.350)$ \\
\hline Slightly more significant & $(1.100,1.150,1.200)$ \\
\hline Almost equal value & $(1.000,1.000,1.050)$ \\
\hline Equal value & $(1.000,1.000,1.000)$ \\
\hline
\end{tabular}

Table 2. The linguistic variables for the evaluation of the criteria (Scale 0-1) (Stević et al., 2018)

\begin{tabular}{|l|c|}
\hline \multicolumn{1}{|c|}{ Linguistic variables } & Fuzzy Numbers \\
\hline Absolutely less significant & $(0.222,0.250,0.286)$ \\
\hline Dominantly less significant & $(0.250,0.286,0.333)$ \\
\hline Much less significant & $(0.286,0.333,0.400)$ \\
\hline Really less significant & $(0.333,0.400,0.500)$ \\
\hline Less significant & $(0.400,0.500,0.667)$ \\
\hline Moderately less significant & $(0.500,0.667,1.000)$ \\
\hline Weakly less significant & $(0.667,1.000,1.000)$ \\
\hline
\end{tabular}

Step 1-3: If $j=1$, the $\widetilde{c_{j}}=\left(c_{j}^{l}, c_{j}^{m}, c_{j}^{u}\right)$ coefficient is determined as $\tilde{1}$. Otherwise $(j>1)$, $\widetilde{c_{j}}=\left(c_{j}^{l}, c_{j}^{m}, c_{j}^{u}\right)$ coefficient is calculated as follows:

$$
\widetilde{c_{j}}=\left(c_{j}^{l}, c_{j}^{m}, c_{j}^{u}\right)=2-\tilde{e_{j}}=\left(\left(2-e_{j}^{u}\right),\left(2-e_{j}^{m}\right),\left(2-e_{j}^{l}\right)\right) .
$$

Step 1-4: If $j=1$, the $\widetilde{q_{j}}=\left(q_{j}^{l}, q_{j}^{m}, q_{j}^{u}\right)$ fuzzy weight is determined as $\tilde{1}$. Otherwise $(j>1)$, the $\widetilde{q_{j}}=\left(q_{j}^{l}, q_{j}^{m}, q_{j}^{u}\right)$ fuzzy weight is computed as follows: 


$$
\widetilde{q_{j}}=\left(q_{j}^{l}, q_{j}^{m}, q_{j}^{u}\right)=\frac{\widetilde{q_{j-1}}}{\widetilde{c_{j}}}=\left(\frac{q_{j-1}^{l}}{c_{j}^{u}}, \frac{q_{j-1}^{m}}{c_{j}^{m}}, \frac{q_{j-1}^{u}}{c_{j}^{l}}\right) .
$$

Step 1-5: The fuzzy relative weight $\left(\widetilde{w_{j}}=\left(w_{j}^{l}, w_{j}^{m}, w_{j}^{u}\right)\right)$ of the $j$ th criterion is computed as follows:

$$
\widetilde{w_{j}}=\left(w_{j}^{l}, w_{j}^{m}, w_{j}^{u}\right)=\frac{\widetilde{q_{j}}}{\sum_{j=1}^{n} \widetilde{q_{j}}}=\left(\frac{q_{j}^{l}}{\sum_{j=1}^{n} q_{j}^{u}}, \frac{q_{j}^{m}}{\sum_{j=1}^{n} q_{j}^{m}}, \frac{q_{j}^{u}}{\sum_{j=1}^{n} q_{j}^{l}}\right) .
$$

The steps of the inverse methodology of the fuzzy PIPRECIA method are indicated in the next steps.

Step 1-6: The procedure in Step 1-2 is repeated, but this time, it starts from the penultimate criterion.

$$
\widetilde{e_{j}^{r^{\prime}}}=\left\{\begin{array}{lll}
>\tilde{1} & \text { if } & C_{j}>C_{j-1} \\
=\tilde{1} & \text { if } & C_{j}=C_{j-1} \\
<\tilde{1} & \text { if } & C_{j}<C_{j-1}
\end{array} .\right.
$$

In Eq. (5), $\widetilde{e_{j}^{r^{\prime}}}$ is the evaluation of the jth criterion by the DM $r$. All $\widetilde{e_{j}^{\prime}}$ values are aggregated by using the geometric mean in order to achieve $\widetilde{e_{j}^{\prime}}\left(e_{j}^{l^{\prime}}, e_{j}^{m^{\prime}}, e_{j}^{u^{\prime}}\right)$.

Step 1-7: If $j=1$, the $\widetilde{c_{j}^{\prime}}=\left(c_{j}^{l^{\prime}}, c_{j}^{m^{\prime}}, c_{j}^{u^{\prime}}\right)$ coefficient is determined as $\tilde{1}$. Otherwise $(j>1)$, the $\widetilde{c_{j}^{\prime}}=\left(c_{j}^{l^{\prime}}, c_{j}^{m^{\prime}}, c_{j}^{u^{\prime}}\right)$ coefficient is calculated as follows:

$$
\widetilde{c_{j}^{\prime}}=\left(c_{j}^{l^{\prime}}, c_{j}^{m^{\prime}}, c_{j}^{u^{\prime}}\right)=2-\widetilde{e_{j}^{\prime}}=\left(\left(2-e_{j}^{u^{\prime}}\right),\left(2-e_{j}^{m^{\prime}}\right),\left(2-e_{j}^{l^{\prime}}\right)\right) \text {. }
$$

Step 1-8: If $j=1$, the $\widetilde{q_{j}^{\prime}}=\left(q_{j}^{l^{\prime}}, q_{j}^{m^{\prime}}, q_{j}^{u^{\prime}}\right)$ fuzzy weight is determined as $\tilde{1}$. Otherwise $(j>1)$, the $q_{j}^{\prime}=\left(q_{j}^{l^{\prime}}, q_{j}^{m^{\prime}}, q_{j}^{u^{\prime}}\right)$ fuzzy weight is computed as follows:

$$
\widetilde{q_{j}^{\prime}}=\left(q_{j}^{l^{\prime}}, q_{j}^{m^{\prime}}, q_{j}^{u^{\prime}}\right)=\frac{\widetilde{q_{j-1}^{\prime}}}{\widetilde{c_{j}^{\prime}}}=\left(\frac{q_{j-1}^{l^{\prime}}}{c_{j}^{u^{\prime}}}, \frac{q_{j-1}^{m^{\prime}}}{c_{j}^{m^{\prime}}}, \frac{q_{j-1}^{u^{\prime}}}{c_{j}^{l^{\prime}}}\right) \text {. }
$$

Step 1-9: The fuzzy relative weight $\left(\widetilde{w_{j}^{\prime}}=\left(w_{j}^{l^{\prime}}, w_{j}^{m^{\prime}}, w_{j}^{u^{\prime}}\right)\right)$ of the $j$ th criterion is computed as follows:

$$
\widetilde{w_{j}^{\prime}}=\left(w_{j}^{l^{\prime}}, w_{j}^{m^{\prime}}, w_{j}^{u^{\prime}}\right)=\frac{\widetilde{q_{j}^{\prime}}}{\sum_{j=1}^{n} \widetilde{\widetilde{q_{j}^{\prime}}}}=\left(\frac{q_{j}^{l^{\prime}}}{\sum_{j=1}^{n} q_{j}^{u^{\prime}}}, \frac{q_{j}^{m^{\prime}}}{\sum_{j=1}^{n} q_{j}^{m^{\prime}}}, \frac{q_{j}^{u^{\prime}}}{\sum_{j=1}^{n} q_{j}^{l^{\prime}}}\right) .
$$

Step 1-10: The fuzzy subjective weight $\left(\widetilde{w_{j s}}=\left(w_{j s}^{l}, w_{j s}^{m}, w_{j s}^{u}\right)\right)$ of the $j$ th criterion is calculated as follows.

$$
\widetilde{w_{j s}}=\left(w_{j s}^{l}, w_{j s}^{m}, w_{j s}^{u}\right)=\frac{\widetilde{w_{j}}+\widetilde{w_{j}^{\prime}}}{2}=\left(\frac{w_{j}^{l}+w_{j}^{l^{\prime}}}{2}, \frac{w_{j}^{m}+w_{j}^{m^{\prime}}}{2}, \frac{w_{j}^{u}+w_{j}^{u^{\prime}}}{2}\right) .
$$

After obtaining the fuzzy subjective weights of the criteria $\left(\widetilde{w_{j s}}\right)$, the fuzzy objective weights of the criteria $\left(\widetilde{w_{j o}}\right)$ are calculated by using the fuzzy PSI method. 


\subsection{Fuzzy PSI}

In this case, the combination of the objective and subjective criteria weights are used. But, the decision-maker could decide whether to involve the objective weights or not. For the purpose of this work, fuzzy PSI is utilized to obtain the fuzzy objective weights of the criteria $\left(\widetilde{w_{j o}}\right)$. The steps of the fuzzy PSI are explained as follows:

Step 2-1: DMs evaluate the alternatives with the help of the linguistic values shown in Table 3. All of the DMs' fuzzy judgments are aggregated by using the geometric mean to achieve the aggregated fuzzy decision matrix $(\tilde{Z})$, as indicated in Eq. (10).

Table 3. The linguistic variables and fuzzy numbers (Stanujkic, 2015)

\begin{tabular}{|l|c|}
\hline \multicolumn{1}{|c|}{ Linguistic variables } & Fuzzy numbers \\
\hline Very high & $(0.9,1.0,1.0)$ \\
\hline High & $(0.7,0.9,1.0)$ \\
\hline Medium high & $(0.5,0.7,0.9)$ \\
\hline Medium & $(0.3,0.5,0.7)$ \\
\hline Medium low & $(0.1,0.3,0.5)$ \\
\hline Low & $(0.0,0.1,0.3)$ \\
\hline Very low & $(0.0,0.0,0.1)$ \\
\hline
\end{tabular}

$$
\tilde{Z}=\left[\widetilde{z_{i j}}\right]_{k \times n}=\left[\begin{array}{ccc}
\widetilde{z_{11}} & \cdots & \widetilde{z_{1 n}} \\
\vdots & \ddots & \vdots \\
\widetilde{z_{k 1}} & \cdots & \widetilde{z_{k n}}
\end{array}\right] .
$$

In Eq. (10), $\widetilde{z_{i j}}\left(z_{i j}^{l}, z_{i j}^{m}, z_{i j}^{u}\right)$ is the fuzzy value of the $i$ th alternative of the $j$ th criterion.

Step 2-2: This matrix is normalized by using Eqs (11) (for the non-beneficial criteria) and 12 (for the beneficial criteria). The normalization procedure is indicated as follows:

$$
\begin{gathered}
\widetilde{t_{i j}}=\left(t_{i j}^{l}, t_{i j}^{m}, t_{i j}^{u}\right)=\frac{\min \left(\widetilde{z_{i j}}\right)}{\widetilde{z_{i j}}}=\left(\frac{\min \left(z_{i j}^{l}\right)}{z_{i j}^{u}}, \frac{\min \left(z_{i j}^{l}\right)}{z_{i j}^{m}}, \frac{\min \left(z_{i j}^{l}\right)}{z_{i j}^{l}}\right) ; \\
\widetilde{t_{i j}}=\left(t_{i j}^{l}, t_{i j}^{m}, t_{i j}^{u}\right)=\frac{\widetilde{z_{i j}}}{\max \left(\widetilde{z_{i j}}\right)}=\left(\frac{z_{i j}^{l}}{\max \left(z_{i j}^{u}\right)}, \frac{z_{i j}^{m}}{\max \left(z_{i j}^{u}\right)}, \frac{z_{i j}^{u}}{\max \left(z_{i j}^{u}\right)}\right) .
\end{gathered}
$$

In Eqs (11) and (12), $\widetilde{t_{i j}}$ is the normalized value of $\widetilde{z_{i j}}$.

Step 2-3: The arithmetic mean $\left(\widetilde{\bar{t}_{i j}}\left(\bar{t}_{i j}^{l}, \bar{t}_{i j}^{m}, \bar{t}_{i j}^{u}\right)\right)$ for each criterion is computed as follows:

$$
\widetilde{\widetilde{t_{i j}}}=\left(\bar{t}_{i j}^{l}, \bar{t}_{i j}^{m}, \bar{t}_{i j}^{u}\right)=\frac{\sum_{i=1}^{k} \widetilde{t_{i j}}}{k}=\left(\frac{\sum_{i=1}^{k} t_{i j}^{l}}{k}, \frac{\sum_{i=1}^{k} t_{i j}^{m}}{k}, \frac{\sum_{i=1}^{k} t_{i j}^{u}}{k}\right) .
$$


Step 2-4: For each criterion, the fuzzy preference value $\left(\widetilde{P V_{j}}\left(P V_{j}^{l}, P V_{j}^{m}, P V_{j}^{u}\right)\right)$ is computed as follows:

$$
\begin{aligned}
& \widetilde{P V_{j}}=\left(P V_{j}^{l}, P V_{j}^{m}, P V_{j}^{u}\right)=\sum_{i=1}^{k}\left(\widetilde{t_{i j}}-\widetilde{t_{i j}}\right)^{2}=\left(\min \left(\sum_{i=1}^{k}\left(t_{i j}^{l}-\bar{t}_{i j}^{l}\right)^{2}, \sum_{i=1}^{k}\left(t_{i j}^{u}-\bar{t}_{i j}^{u}\right)^{2}\right),\right. \\
& \sum_{i=1}^{k}\left(t_{i j}^{m}-\bar{t}_{i j}^{m}\right)^{2}, \max \left(\sum_{i=1}^{k}\left(t_{i j}^{l}-\bar{t}_{i j}^{l}\right)^{2}, \sum_{i=1}^{k}\left(t_{i j}^{u}-\bar{t}_{i j}^{u}\right)^{2}\right) .
\end{aligned}
$$

Step 2-5: For each criterion, the fuzzy deviation value $\left(\widetilde{\rho_{j}}\left(\rho_{j}^{l}, \rho_{j}^{m}, \rho_{j}^{u}\right)\right)$ is calculated by applying Eq. (15) (Ulutaş et al., 2019) as follows:

$$
\widetilde{\rho_{j}}=\left(\rho_{j}^{l}, \rho_{j}^{m}, \rho_{j}^{u}\right)=\left|1-\widetilde{P V_{j}}\right|=\left(\left|1-P V_{j}^{u}\right|,\left|1-P V_{j}^{m}\right|,\left|1-P V_{j}^{l}\right|\right) \text {. }
$$

Step 2-6: In the final step, the objective weight $\left(\widetilde{w_{j o}}\left(w_{j o}^{l}, w_{j o}^{m}, w_{j o}^{u}\right)\right)$ of each criterion is computed as follows:

$$
\widetilde{w_{j o}}=\left(w_{j o}^{l}, w_{j o}^{m}, w_{j o}^{u}\right)=\frac{\widetilde{\rho_{j}}}{\sum_{j=1}^{n} \widetilde{\rho_{j}}}=\left(\frac{\rho_{j}^{l}}{\sum_{j=1}^{n} \rho_{j}^{u}}, \frac{\rho_{j}^{m}}{\sum_{j=1}^{n} \rho_{j}^{m}}, \frac{\rho_{j}^{u}}{\sum_{j=1}^{n} \rho_{j}^{l}}\right) .
$$

The fuzzy subjective and objective weights of the criteria are aggregated by using the fuzzy extension of the Zavadskas and Podvezko (2016) method. The aggregation process is indicated in Eq. (17) as follows:

$$
\widetilde{w_{j c}}=\left(w_{j c}^{l}, w_{j c}^{m}, w_{j c}^{u}\right)=\frac{\widetilde{w_{j s} w_{j o}}}{\sum_{j=1}^{n} \widetilde{w_{j s} w_{j o}}}=\left(\frac{w_{j s}^{l} w_{j o}^{l}}{\sum_{j=1}^{n} w_{j s}^{u} w_{j o}^{u}}, \frac{w_{j s}^{m} w_{j o}^{m}}{\sum_{j=1}^{n} w_{j s}^{m} w_{j o}^{m}}, \frac{w_{j s}^{u} w_{j o}^{u}}{\sum_{j=1}^{n} w_{j s}^{l} w_{j o}^{l}}\right) .
$$

In Eq. (17), $\widetilde{w_{j c}}$ denotes the fuzzy combined weight of the $j$ th criterion.

\subsection{Fuzzy CoCoSo}

Fuzzy CoCoSo is used to rank the alternatives with respect to their performances. The steps of the fuzzy CoCoSo are explained in the following manner:

Step 3-1: The Fuzzy decision matrix $(\tilde{Z})$ has already been constructed in Eq. (10), so we may continue with the step 3-2.

Step 3-2: This matrix is normalized by using Eqs (18) (for the non-beneficial criteria) and 19 (for the beneficial criteria), namely in the following manner:

$$
\begin{aligned}
& \tilde{r}_{i j}=\left(r_{i j}^{l}, r_{i j}^{m}, r_{i j}^{u}\right)=\frac{\max \left(\widetilde{z_{i j}}\right)-\widetilde{z_{i j}}}{\max \left(\widetilde{z_{i j}}\right)-\min \left(\widetilde{z_{i j}}\right)}= \\
& \left(\frac{\max \left(z_{i j}^{u}\right)-z_{i j}^{u}}{\max \left(z_{i j}^{u}\right)-\min \left(z_{i j}^{l}\right)}, \frac{\max \left(z_{i j}^{u}\right)-z_{i j}^{m}}{\max \left(z_{i j}^{u}\right)-\min \left(z_{i j}^{l}\right)}, \frac{\max \left(z_{i j}^{u}\right)-z_{i j}^{l}}{\max \left(z_{i j}^{u}\right)-\min \left(z_{i j}^{l}\right)}\right) ;
\end{aligned}
$$




$$
\begin{aligned}
& \widetilde{r_{i j}}=\left(r_{i j}^{l}, r_{i j}^{m}, r_{i j}^{u}\right)=\frac{\widetilde{z_{i j}}-\min \left(\widetilde{z_{i j}}\right)}{\max \left(\widetilde{z_{i j}}\right)-\min \left(\widetilde{z_{i j}}\right)}= \\
& \left(\frac{z_{i j}^{l}-\min \left(z_{i j}^{l}\right)}{\max \left(z_{i j}^{u}\right)-\min \left(z_{i j}^{l}\right)}, \frac{z_{i j}^{m}-\min \left(z_{i j}^{l}\right)}{\max \left(z_{i j}^{u}\right)-\min \left(z_{i j}^{l}\right)}, \frac{z_{i j}^{u}-\min \left(z_{i j}^{l}\right)}{\max \left(z_{i j}^{u}\right)-\min \left(z_{i j}^{l}\right)}\right) .
\end{aligned}
$$

In Eqs (18)-(19), $\widetilde{r_{i j}}$ is the normalized value of $\widetilde{z_{i j}}$.

Step 3-3: The fuzzy sum of the weighted comparability $\left(\widetilde{S}_{i}\left(S_{i}^{l}, S_{i}^{m}, S_{i}^{u}\right)\right)$ and the power weight of the comparability sequences $\left(\widetilde{P}_{i}\left(P_{i}^{l}, P_{i}^{m}, P_{i}^{u}\right)\right)$ for each alternative are computed as follows:

$$
\begin{aligned}
& \widetilde{S_{i}}=\left(S_{i}^{l}, S_{i}^{m}, S_{i}^{u}\right)=\sum_{j=1}^{n} \widetilde{w_{j c}} \widetilde{r_{i j}}=\left(\sum_{j=1}^{n} w_{j c}^{l} r_{i j}^{l}, \sum_{j=1}^{n} w_{j c}^{m} r_{i j}^{m}, \sum_{j=1}^{n} w_{j c}^{u} r_{i j}^{u}\right) ; \\
& \widetilde{P}_{i}=\left(P_{i}^{l}, P_{i}^{m}, P_{i}^{u}\right)=\sum_{j=1}^{n}\left(\widetilde{r_{i j}}\right)^{\widetilde{w_{j c}}}=\left(\sum_{j=1}^{n}\left(r_{i j}^{l}\right)^{w_{j c}^{u}}, \sum_{j=1}^{n}\left(r_{i j}^{m}\right)^{w_{j c}^{m}}, \sum_{j=1}^{n}\left(r_{i j}^{u}\right)^{w_{j c}^{l}}\right) .
\end{aligned}
$$

Step 3-4: Three aggregation strategies are applied to obtain three fuzzy appraisal scores $\left(\widetilde{f_{i a}}, \widetilde{f_{i b}}, \widetilde{f_{i c}}\right)$.

$\widetilde{f_{i a}}=\left(f_{i a}^{l}, f_{i a}^{m}, f_{i a}^{u}\right)=\frac{\widetilde{P}_{i}+\widetilde{S}_{i}}{\sum_{i=1}^{k}\left(\widetilde{P}_{i}+\widetilde{S}_{i}\right)}=$

$\left(\frac{P_{i}^{l}+S_{i}^{l}}{\sum_{i=1}^{k}\left(P_{i}^{u}+S_{i}^{u}\right)}, \frac{P_{i}^{m}+S_{i}^{m}}{\sum_{i=1}^{k}\left(P_{i}^{m}+S_{i}^{m}\right)}, \frac{P_{i}^{u}+S_{i}^{u}}{\sum_{i=1}^{k}\left(P_{i}^{l}+S_{i}^{l}\right)}\right)$

$\widetilde{f_{i b}}=\left(f_{i b}^{l}, f_{i b}^{m}, f_{i b}^{u}\right)=\frac{\widetilde{S_{i}}}{\min \left(\widetilde{\left.S_{i}\right)}\right.}+\frac{\widetilde{P_{i}}}{\min \left(\widetilde{\left.P_{i}\right)}\right.}=$

$\left(\frac{S_{i}^{l}}{\min \left(S_{i}^{l}\right)}+\frac{P_{i}^{l}}{\min \left(P_{i}^{l}\right)}, \frac{S_{i}^{m}}{\min \left(S_{i}^{l}\right)}+\frac{P_{i}^{m}}{\min \left(P_{i}^{l}\right)}, \frac{S_{i}^{u}}{\min \left(S_{i}^{l}\right)}+\frac{P_{i}^{u}}{\min \left(P_{i}^{l}\right)}\right)$;

$\widetilde{f_{i c}}=\left(f_{i c}^{l}, f_{i c}^{m}, f_{i c}^{u}\right)=\frac{\lambda\left(\widetilde{S}_{i}\right)+(1-\lambda)\left(\widetilde{P}_{i}\right)}{\lambda \max \left(\widetilde{S_{i}}\right)+(1-\lambda) \max \left(\widetilde{P_{i}}\right)}=$

$\left(\frac{\lambda\left(S_{i}^{l}\right)+(1-\lambda)\left(P_{i}^{l}\right)}{\lambda \max \left(S_{i}^{u}\right)+(1-\lambda) \max \left(P_{i}^{u}\right)}, \frac{\lambda\left(S_{i}^{m}\right)+(1-\lambda)\left(P_{i}^{m}\right)}{\lambda \max \left(S_{i}^{u}\right)+(1-\lambda) \max \left(P_{i}^{u}\right)}, \frac{\lambda\left(S_{i}^{u}\right)+(1-\lambda)\left(P_{i}^{u}\right)}{\lambda \max \left(S_{i}^{u}\right)+(1-\lambda) \max \left(P_{i}^{u}\right)}\right.$.

In Eq. (24), $\lambda$ is usually taken as 0.5 and this value is determined by DMs.

Step 3-5: The fuzzy appraisal scores $\left(\widetilde{f_{i a}}, \widetilde{f_{i b}}, \widetilde{f_{i c}}\right)$ are converted into crisp appraisal scores $\left(f_{i a}, f_{i b}, f_{i c}\right)$ by using Eqs $(25)-(27)$. 


$$
\begin{aligned}
& f_{i a}=\frac{f_{i a}^{l}+f_{i a}^{m}+f_{i a}^{u}}{3} ; \\
& f_{i b}=\frac{f_{i b}^{l}+f_{i b}^{m}+f_{i b}^{u}}{3} ; \\
& f_{i c}=\frac{f_{i c}^{l}+f_{i c}^{m}+f_{i c}^{u}}{3} .
\end{aligned}
$$

Step 3-6: The crisp appraisal scores are combined to obtain the final score $\left(f_{i}\right)$ for each alternative by using Eq. (28).

$$
f_{i}=\left(f_{i a} f_{i b} f_{i c}\right)^{1 / 3}+\left(\frac{1}{3}\right)\left(f_{i a}+f_{i b}+f_{i c}\right) .
$$

The alternative with the highest score is the best alternative.

\section{The application of the Hybrid Model}

The proposed model was applied to a textile workshop which produces ready-garments for retailers in different cities. This workshop would like to distribute its products to retailers by engaging a transportation company. An integrated fuzzy MCDM model including fuzzy PIPRECIA, fuzzy PSI, and fuzzy CoCoSo was proposed to determine the most suitable transport company for the workshop. The data used in the decision-making process were obtained from a team of managers including five managers working in the workshop. The team identified the criteria for the assessment process and accepted the criteria for the assessment process proposed by Kulak and Kahraman (2005) and Kabir (2015), and added the Transportation Capacity criterion. All the criteria are presented as follows: Cost of Service (CS); Flexibility (FLX); Complementary Service (CSE); Work Experience (WE); Delivery Time (DT); Reputation (R); Transportation Capacity (TCP). The CS and DT criteria were considered as the non-beneficial criteria, whereas the other criteria were considered as the beneficial. Each manager of the team assessed the above criteria. The geometric mean was utilized to combine individual evaluations. The assessments of fuzzy PIPRECIA and inverse fuzzy PIPRECIA are shown in Table 4 and Table 5, respectively.

Table 4. The fuzzy PIPRECIA assessment

\begin{tabular}{|c|c|c|c|}
\hline Criteria & Managers & Manager 1 & Manger 3 \\
\hline CS & & & \\
\hline DT & $(0.4,0.5,0.667)$ & $(0.333,0.4,0.5)$ & $(0.333,0.4,0.5)$ \\
\hline TCP & $(0.4,0.5,0.667)$ & $(1.1,1.15,1.2)$ & $(0.333,0.4,0.5)$ \\
\hline R & $(0.286,0.333,0.4)$ & $(0.5,0.667,1)$ & $(0.286,0.333,0.4)$ \\
\hline WE & $(0.286,0.333,0.4)$ & $(1.2,1.3,1.35)$ & $(0.4,0.5,0.667)$ \\
\hline CSE & $(0.4,0.5,0.667)$ & $(1.2,1.3,1.35)$ & $(1.3,1.45,1.5)$ \\
\hline FLX & $(0.333,0.4,0.5)$ & $(0.5,0.667,1)$ & $(0.286,0.333,0.4)$ \\
\hline
\end{tabular}


End of Table 4

\begin{tabular}{|c|c|c|c|}
\hline $\begin{array}{ll}\text { Criteria } & \text { Managers }\end{array}$ & Manager 4 & Manager 5 & Manger 6 \\
\hline \multicolumn{4}{|l|}{$\mathrm{CS}$} \\
\hline DT & $(0.4,0.5,0.667)$ & $(0.333,0.4,0.5)$ & $(0.358,0.437,0.561)$ \\
\hline TCP & $(1.1,1.15,1.2)$ & $(0.4,0.5,0.667)$ & $(0.578,0.667,0.796)$ \\
\hline $\mathrm{R}$ & $(0.667,1,1)$ & $(0.5,0.667,1)$ & $(0.424,0.548,0.693)$ \\
\hline WE & $(1.1,1.15,1.2)$ & $(0.333,0.4,0.5)$ & $(0.550,0.630,0.736)$ \\
\hline CSE & $(0.286,0.333,0.4)$ & $(1.2,1.3,1.35)$ & $(0.735,0.836,0.939)$ \\
\hline FLX & $(0.4,0.5,0.667)$ & $(0.286,0.333,0.4)$ & $(0.353,0.431,0.556)$ \\
\hline
\end{tabular}

Table 5. The inverse fuzzy PIPRECIA assessment

\begin{tabular}{|c|c|c|c|}
\hline Criteria & Managers & Manager 2 & Manger 3 \\
\hline FLX & & & \\
\hline CSE & $(1.2,1.3,1.35)$ & $(1.1,1.15,1.2)$ & $(1.1,1.15,1.2)$ \\
\hline WE & $(1.1,1.15,1.2)$ & $(0.286,0.333,0.4)$ & $(1.1,1.15,1.2)$ \\
\hline R & $(1.4,1.6,1.65)$ & $(1.4,1.6,1.65)$ & $(1.1,1.15,1.2)$ \\
\hline TCP & $(1.4,1.6,1.65)$ & $(0.333,0.4,0.5)$ & $(1.2,1.3,1.35)$ \\
\hline DT & $(1.2,1.3,1.35)$ & $(0.333,0.4,0.5)$ & $(0.333,0.4,0.5)$ \\
\hline CS & $(1.1,1.15,1.2)$ & $(1.1,1.15,1.2)$ & $(1.1,1.15,1.2)$ \\
\hline Managers & Manager 4 & Manager 5 & Manger 6 \\
\hline Criteria & & & $(1.159,1.238,1.288)$ \\
\hline FLX & $(1.2,1.3,1.35)$ & $(1.2,1.3,1.35)$ & $(0.673,0.745,0.828)$ \\
\hline CSE & $(0.333,0.4,0.5)$ & $(1.2,1.3,1.35)$ & $(1.247,1.363,1.414)$ \\
\hline WE & $(1,1,1.05)$ & $(1.4,1.6,1.65)$ & $(0.804,0.937,1.085)$ \\
\hline R & $(0.5,0.667,1)$ & $(1.2,1.3,1.35)$ & $(0.573,0.668,0.774)$ \\
\hline TCP & $(1.4,1.6,1.65)$ & $(0.333,0.4,0.5)$ & $(1.1,1.15,1.2)$ \\
\hline DT & $(1.1,1.15,1.2)$ & $(1.1,1.15,1.2)$ & \\
\hline CS & \multicolumn{3}{|c}{}
\end{tabular}

The results of fuzzy PIPRECIA were obtained by using Eqs (2)-(4). These results are presented in Table 6 .

Table 6. The results of fuzzy PIPRECIA

\begin{tabular}{|l|c|c|c|c|}
\hline Criteria & $\widetilde{e_{j}}$ & $\widetilde{c_{j}}$ & $\widetilde{q_{j}}$ & $\widetilde{w_{j}}$ \\
\hline CS & & $(1,1,1)$ & $(1,1,1)$ & $(0.276,0.330,0.365)$ \\
\hline DT & $(0.358,0.437,0.561)$ & $(1.439,1.563,1.642)$ & $(0.609,0.640,0.695)$ & $(0.168,0.211,0.254)$ \\
\hline TCP & $(0.578,0.667,0.796)$ & $(1.204,1.333,1.422)$ & $(0.428,0.480,0.577)$ & $(0.118,0.158,0.211)$ \\
\hline R & $(0.424,0.548,0.693)$ & $(1.307,1.452,1.576)$ & $(0.272,0.331,0.441)$ & $(0.075,0.109,0.161)$ \\
\hline WE & $(0.550,0.630,0.736)$ & $(1.264,1.370,1.450)$ & $(0.188,0.242,0.349)$ & $(0.052,0.080,0.128)$ \\
\hline CSE & $(0.735,0.836,0.939)$ & $(1.061,1.164,1.265)$ & $(0.149,0.208,0.329)$ & $(0.041,0.069,0.120)$ \\
\hline FLX & $(0.353,0.431,0.556)$ & $(1.444,1.569,1.647)$ & $(0.090,0.133,0.228)$ & $(0.025,0.044,0.083)$ \\
\hline
\end{tabular}


The results of inverse fuzzy PIPRECIA were obtained by using Eqs (6)-(8). These results are presented in Table 7.

Table 7. The results of inverse fuzzy PIPRECIA

\begin{tabular}{|c|c|c|c|c|}
\hline Criteria & $\widetilde{e_{j}^{\prime}}$ & $\widetilde{c_{j}^{\prime}}$ & $\widetilde{q_{j}^{\prime}}$ & $\widetilde{w_{j}^{\prime}}$ \\
\hline FLX & & $(1,1,1)$ & $(1,1,1)$ & $(0.083,0.110,0.148)$ \\
\hline CSE & $(1.159,1.238,1.288)$ & $(0.712,0.762,0.841)$ & $(1.189,1.312,1.404)$ & $(0.099,0.145,0.208)$ \\
\hline WE & $(0.673,0.745,0.828)$ & $(1.172,1.255,1.327)$ & $(0.896,1.045,1.198)$ & $(0.075,0.115,0.178)$ \\
\hline R & $(1.247,1.363,1.414)$ & $(0.586,0.637,0.753)$ & $(1.190,1.641,2.044)$ & $(0.099,0.181,0.303)$ \\
\hline TCP & $(0.804,0.937,1.085)$ & $(0.915,1.063,1.196)$ & $(0.995,1.544,2.234)$ & $(0.083,0.170,0.331)$ \\
\hline DT & $(0.573,0.668,0.774)$ & $(1.226,1.332,1.427)$ & $(0.697,1.159,1.822)$ & $(0.058,0.128,0.270)$ \\
\hline CS & $(1.1,1.15,1.2)$ & $(0.8,0.85,0.9)$ & $(0.774,1.364,2.278)$ & $(0.065,0.150,0.338)$ \\
\hline
\end{tabular}

The results of fuzzy PIPRECIA and inverse fuzzy PIPRECIA were combined so as to obtain the fuzzy subjective weights of the criteria $\left(\widetilde{w_{j s}}\right)$. These weights are illustrated in Table 8 .

Table 8 . The subjective weights of the criteria

\begin{tabular}{|c|c|}
\hline Criteria & Results \\
\hline & $\widetilde{w_{j s}}$ \\
\hline CS & $(0.171,0.240,0.352)$ \\
\hline DT & $(0.113,0.170,0.262)$ \\
\hline TCP & $(0.101,0.164,0.271)$ \\
\hline R & $(0.087,0.145,0.232)$ \\
\hline WE & $(0.064,0.098,0.153)$ \\
\hline CSE & $(0.070,0.107,0.164)$ \\
\hline FLX & $(0.054,0.077,0.116)$ \\
\hline
\end{tabular}

After obtaining the fuzzy subjective weights of the criteria $\left(\widetilde{w_{j s}}\right)$, the fuzzy objective weights of the criteria $\left(\widetilde{w_{j o}}\right)$ were calculated by using the fuzzy PSI method.

The team of the managers identified five transportation companies (TFRs) and the managers individually evaluated the performance of those companies. A fuzzy decision matrix was constructed by using the geometric mean to aggregate the managers' individual judgements. The matrix is indicated in Table 9. 
Table 9. The fuzzy decision matrix

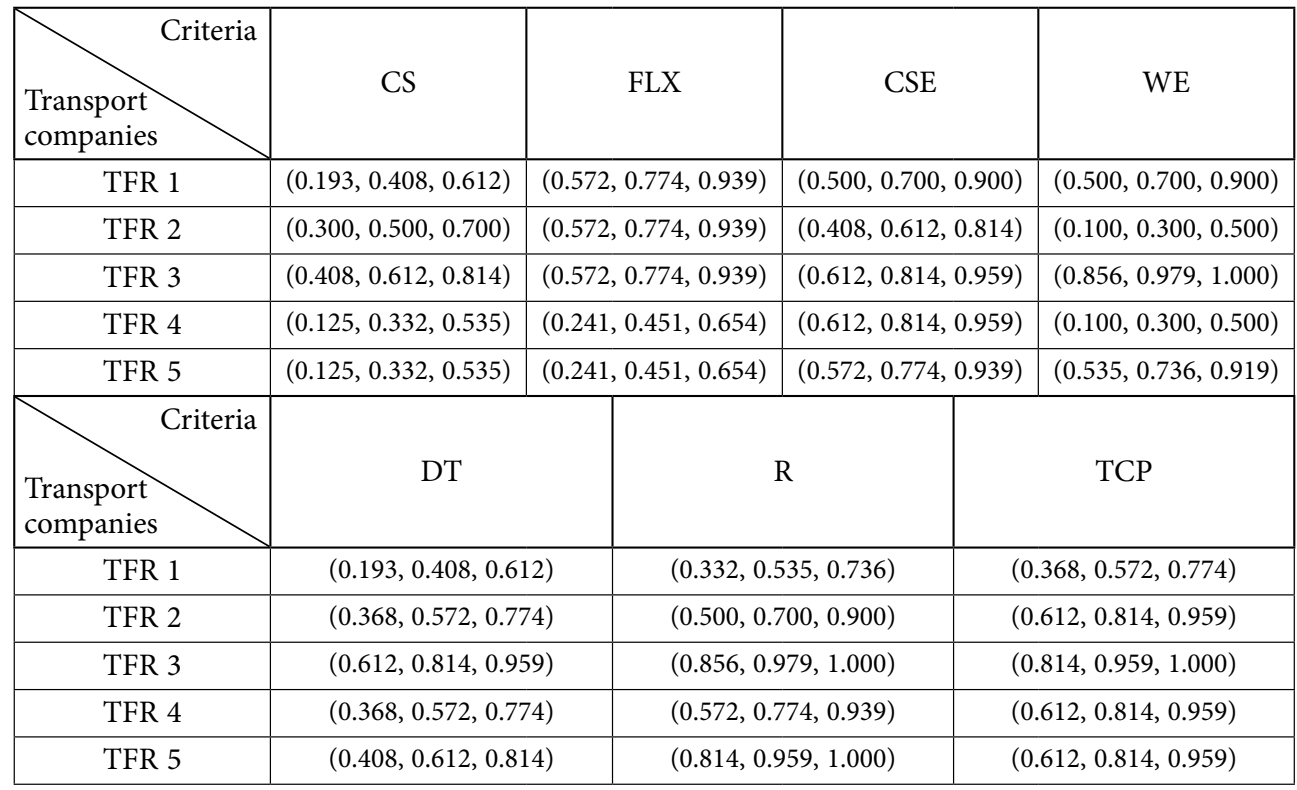

By using Eqs (11)-(16), the results of fuzzy PSI were computed. These results are shown in Table 10.

Table 10. The results of fuzzy PSI

\begin{tabular}{|c|c|c|c|c|c|c|}
\hline $\begin{array}{lll}\text { Results } & \text { Criteria } \\
\end{array}$ & $\mathrm{CS}$ & & FLX & \multicolumn{2}{|l|}{ CSE } & WE \\
\hline$\widetilde{P V_{j}}$ & $(0.005,0.024,0.415)$ & \multicolumn{2}{|c|}{$(0.111,0.142,0.149)$} & \multicolumn{2}{|c|}{$(0.016,0.033,0.033)$} & $(0.238,0.352,0.415)$ \\
\hline$\widetilde{\rho_{j}}$ & $(0.585,0.976,0.995)$ & \multicolumn{2}{|c|}{$(0.851,0.858,0.889)$} & \multicolumn{2}{|c|}{$(0.967,0.967,0.984)$} & $(0.585,0.648,0.762)$ \\
\hline$\widetilde{w_{j o}}$ & $(0.089,0.158,0.183)$ & \multicolumn{2}{|c|}{$(0.130,0.139,0.164)$} & \multicolumn{2}{|l|}{$(0.1$} & $(0.089,0.105,0.140)$ \\
\hline $\begin{array}{ll}\text { Results } & \text { Criteria } \\
\end{array}$ & \multicolumn{2}{|l|}{ DT } & \multicolumn{2}{|c|}{$\mathrm{R}$} & \multicolumn{2}{|r|}{ TCP } \\
\hline$\widetilde{P V_{j}}$ & \multicolumn{2}{|c|}{$(0.007,0.043,0.264)$} & \multicolumn{2}{|c|}{$(0.047,0.138,0.193)$} & \multicolumn{2}{|c|}{$(0.032,0.078,0.100)$} \\
\hline$\widetilde{\rho_{j}}$ & \multicolumn{2}{|c|}{$(0.736,0.957,0.993)$} & \multicolumn{2}{|c|}{$(0.807,0.862,0.953)$} & \multicolumn{2}{|c|}{$(0.900,0.922,0.968)$} \\
\hline$\widetilde{w_{j o}}$ & \multicolumn{2}{|c|}{$(0.112,0.155,0.183)$} & \multicolumn{2}{|c|}{$(0.123,0.139,0.175)$} & \multicolumn{2}{|c|}{$(0.138,0.149,0.178)$} \\
\hline
\end{tabular}

After obtaining the objective weights of the criteria, the subjective weights and the objective weights were combined by using Eq. (17) in order to achieve the combined weights $\left(\widetilde{w_{j c}}\right)$ of the criteria. These weights are presented in Table 11. 
Table 11. The combined weights of the criteria

\begin{tabular}{|c|c|}
\hline Criteria & Combined weights \\
\hline CS & $\widetilde{w_{j c}}$ \\
\hline FLX & $(0.056,0.259,0.852)$ \\
\hline CSE & $(0.026,0.073,0.252)$ \\
\hline WE & $(0.038,0.114,0.393)$ \\
\hline DT & $(0.021,0.070,0.283)$ \\
\hline R & $(0.047,0.180,0.634)$ \\
\hline TC & $(0.039,0.138,0.537)$ \\
\hline & $(0.051,0.167,0.638)$ \\
\hline
\end{tabular}

After obtaining the combined weights of the criteria, the evaluation process continued by using the CoCoSo method. The fuzzy decision matrix was presented in Table 9. The matrix was normalized by using Eqs (18) and (19). The fuzzy normalized matrix is presented in Table 12.

Table 12. The fuzzy normalized decision matrix

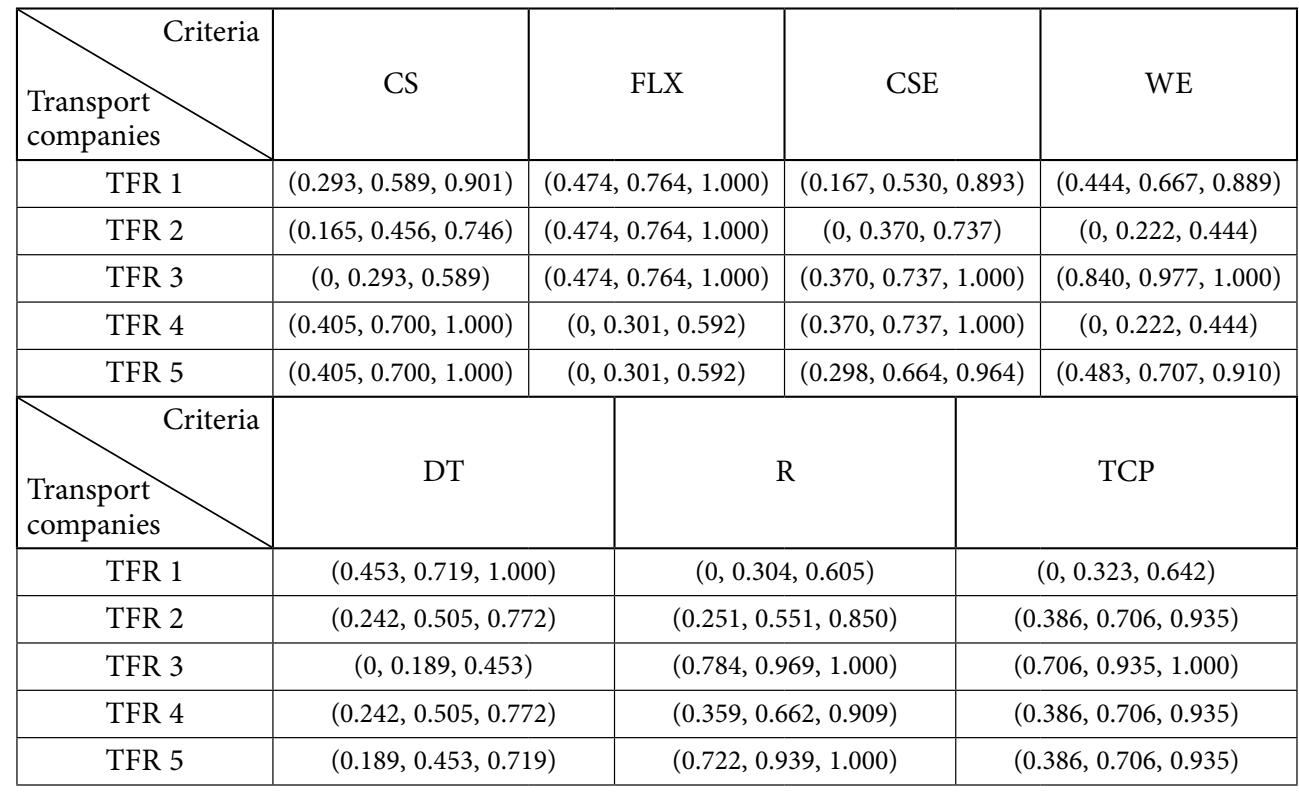

By using Eqs (20) and (21), the fuzzy sum of the weighted comparability $\left(\widetilde{S}_{i}\right)$ and the power weight of the comparability sequences $\left(\widetilde{P}_{i}\right)$ for each transportation company were calculated, respectively. In the computing of these values, the combined weights of the criteria were used as the criteria weights. These values are indicated in Table 13. 
Table 13. The fuzzy sum of the weighted comparability and the power weight of the comparability sequences

\begin{tabular}{|c|c|c|}
\hline Transportation companies & $\widetilde{S}_{i}$ & $\widetilde{P}_{i}$ \\
\hline TFR 1 & $(0.066,0.541,2.991)$ & $(3.075,6.373,6.946)$ \\
\hline TFR 2 & $(0.062,0.516,2.845)$ & $(2.472,6.338,6.933)$ \\
\hline TFR 3 & $(0.111,0.608,2.892)$ & $(4.135,6.398,6.934)$ \\
\hline TFR 4 & $(0.082,0.603,3.094)$ & $(2.668,6.466,6.950)$ \\
\hline TFR 5 & $(0.101,0.657,3.227)$ & $(3.630,6.560,6.964)$ \\
\hline
\end{tabular}

By using Eqs $(22)-(24)$, three fuzzy appraisal scores $\left(\widetilde{f_{i a}}, \widetilde{f_{i b}}, \widetilde{f_{i c}}\right)$ for each transportation company were obtained. The appraisal scores are shown in Table 14.

Table 14. The fuzzy appraisal scores

\begin{tabular}{|c|c|c|c|}
\hline $\begin{array}{c}\text { Transportation } \\
\text { companies }\end{array}$ & $\widetilde{f_{i a}}$ & $\widetilde{f_{i b}}$ & $\widetilde{f}_{i c}$ \\
\hline TFR 1 & $(0.063,0.197,0.606)$ & $(2.308,11.304,51.052)$ & $(0.308,0.678,0.975)$ \\
\hline TFR 2 & $(0.051,0.195,0.596)$ & $(2.000,10.886,48.692)$ & $(0.249,0.673,0.959)$ \\
\hline TFR 3 & $(0.085,0.200,0.599)$ & $(3.463,12.395,49.450)$ & $(0.417,0.687,0.964)$ \\
\hline TFR 4 & $(0.055,0.202,0.612)$ & $(2.402,12.342,52.715)$ & $(0.270,0.694,0.986)$ \\
\hline TFR 5 & $(0.075,0.206,0.621)$ & $(3.097,13.250,54.866)$ & $(0.366,0.708,1.000)$ \\
\hline
\end{tabular}

These fuzzy appraisal scores $\left(\widetilde{f_{i a}}, \widetilde{f_{i b}}, \widetilde{f_{i c}}\right)$ were converted into crisp appraisal scores $\left(f_{i a}, f_{i b}, f_{i c}\right)$ by using Eqs (25)-(27). These crisp scores are presented in Table 15.

Table 15. Crisp Appraisal Scores

\begin{tabular}{|c|c|c|c|}
\hline Transportation companies & $f_{i a}$ & $f_{i b}$ & $f_{i c}$ \\
\hline TFR 1 & 0.289 & 21.555 & 0.654 \\
\hline TFR 2 & 0.281 & 20.526 & 0.627 \\
\hline TFR 3 & 0.295 & 21.769 & 0.689 \\
\hline TFR 4 & 0.290 & 22.486 & 0.650 \\
\hline TFR 5 & 0.301 & 23.738 & 0.691 \\
\hline
\end{tabular}

The foregoing appraisal scores were combined by using Eq. (28) to obtain the final score $\left(f_{i}\right)$ for each transportation company. The final scores and the rankings of the transportation companies are given in Table 16.

According to the results of the fuzzy CoCoSo method, the sequences of the transportation companies are as follows: TFR 5, TFR 4, TFR 3, TFR 1 and TFR 2.

The results of the fuzzy CoCoSo method were compared with the other fuzzy MCDM methods (fuzzy MOORA, fuzzy ARAS, fuzzy WASPAS, fuzzy COPRAS) by applying sensitivity analysis in order to test the accuracy of fuzzy CoCoSo. Figure 1 shows the obtained results of the conducted sensitivity analysis. 
Table 16. The final scores and the rankings of the transportation companies

\begin{tabular}{|c|c|c|}
\hline Transportation companies & $f_{i}$ & Rankings \\
\hline TFR 1 & 9.096 & 4 \\
\hline TFR 2 & 8.680 & 5 \\
\hline TFR 3 & 9.226 & 3 \\
\hline TFR 4 & 9.427 & 2 \\
\hline TFR 5 & 9.946 & 1 \\
\hline
\end{tabular}

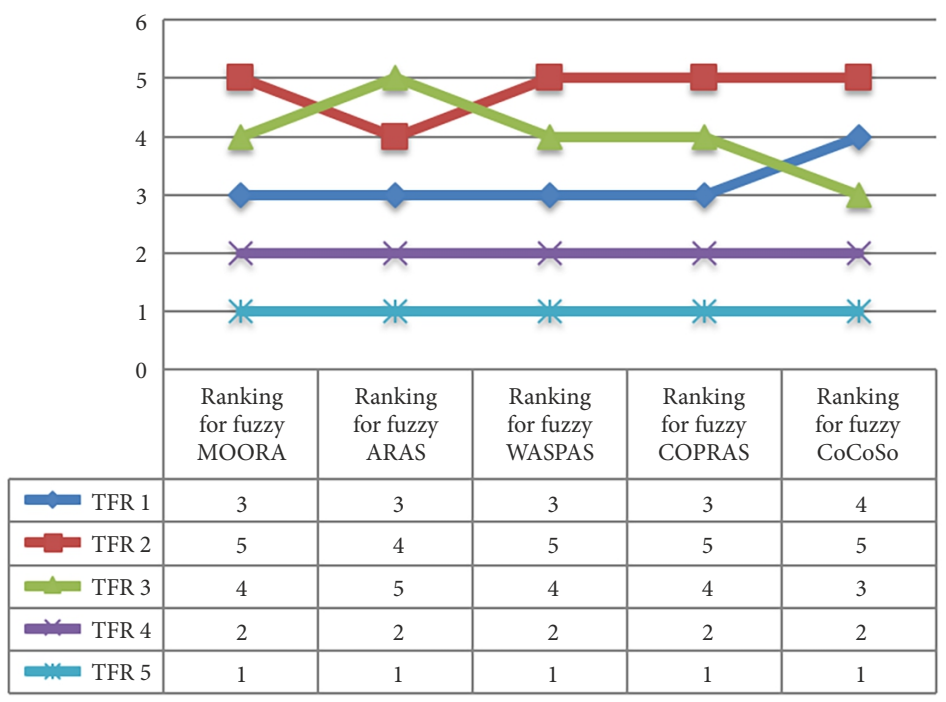

Figure 1. The results of the sensitivity analysis

The correlations between the results of the fuzzy MCDM methods were measured with the Spearman Rho. The correlation coefficients between the fuzzy CoCoSo method and the other fuzzy MCDM methods are as follows: fuzzy CoCoSo-fuzzy MOORA (0.900), fuzzy CoCoSo-fuzzy ARAS (0.700), fuzzy CoCoSo-fuzzy WASPAS (0.900), fuzzy CoCoSo-fuzzy COPRAS (0.900). As can be seen, the correlation coefficients between the fuzzy CoCoSo method and the other fuzzy MCDM methods are very high. As can be concluded, the fuzzy CoCoSo method led to accurate results.

The fuzzy objective weights of the criteria found in the fuzzy PSI method and the subjective weights of the criteria calculated in the fuzzy PIPRECIA method were used separately in the fuzzy CoCoSo method. The ranking of the transportation companies is shown in Table 17.

As can be seen, the change in the weights of the criteria affects the results of the fuzzy CoCoSo method. Therefore, the fuzzy CoCoSo method can be said to be sensitive to change in the weights of the criteria. However, the fuzzy combined weights are thought to have provided more robust results than the individual weights (fuzzy PIPRECIA and fuzzy PSI). 
Table 17. The results of fuzzy CoCoSo w.r.t. change in the criteria weights

\begin{tabular}{|c|c|c|c|}
\hline $\begin{array}{c}\text { Transportation } \\
\text { companies }\end{array}$ & $\begin{array}{c}\text { Rankings } \\
\text { (fuzzy PSI) }\end{array}$ & $\begin{array}{c}\text { Rankings } \\
\text { (fuzzy PIPRECIA) }\end{array}$ & $\begin{array}{c}\text { Rankings } \\
\text { (fuzzy combined weights) }\end{array}$ \\
\hline TFR 1 & 3 & 4 & 4 \\
\hline TFR 2 & 5 & 5 & 5 \\
\hline TFR 3 & 1 & 2 & 3 \\
\hline TFR 4 & 4 & 3 & 1 \\
\hline TFR 5 & 2 & 1 & 2 \\
\hline
\end{tabular}

\section{Conclusions}

In this paper, the application of a hybrid model consisting of the fuzzy PIPRECIA, PSI and CoCoSo methods is proposed for the evaluation and selection of an adequate company for the transportation of goods for a textile workshop. In the evaluation process, a total of five managers were involved, who evaluated the considered alternatives relative to the seven criteria. In the presented case, the significance of the criteria involved in the decision-making process was determined by using the fuzzy PIPRECIA and PSI methods. Both methods are very applicable and easy to use, and the main distinction between them is their subjective or objective orientation. Namely, the PIPRECIA method strongly relies on decision-makers' experiences, whereas the PSI method relies on statistical computations. The weighting results obtained by including the subjective and objective approaches were more representative and the possibility of obtaining biased results was maximally reduced.

The final ranking results were determined by applying the fuzzy CoCoSo method. Although the given method is or a relatively newer date, the same has been used to facilitate the decision-making process in various fields. Scholars have found that the application of the proposed method is quite useful because it is very comprehensive and enables us to make correct and confident decisions. In combination with the previously mentioned PIPRECIA and PSI methods, we formulated an MCDM model suitable to apply in the decision-making process, not only in the field of logistics management, but in other business fields as well. We tested the proposed model by comparing its results with that obtained by applying the fuzzy MOORA, fuzzy WASPAS, fuzzy ARAS and fuzzy COPRAS methods. We conclude that the fuzzy CoCoSo method generates the same results as the rest of the mentioned methods, which proves its stability in this case. Furthermore, we tested the sensitivity of the proposed model by submitting it to change in the weights of the criteria. In that case, we discovered that the CoCoSo method was slightly non-resistant to change in the weights, which had effects on the final ranking order. The deviations, however, were not too serious, so we determined that the application of the fuzzy CoCoSo method in the evaluation of the considered alternatives of a different kind was absolutely justified. Our proposal for future research is in favor of the further examination of the possibilities of the proposed hybrid models in different fields and proposing different extensions to it, such as extensions based on the use of grey or neutrosophic numbers. Also, by involving a larger number of managers and experts in the decision-making process, the final results would be more representative and reliable. Nevertheless, the significance and usefulness of the proposed hybrid model cannot be denied. 


\section{Author contributions}

$\mathrm{AU}, \mathrm{DK}$, and GP were responsible for conceptualization and design. AU, DK, and DS were responsible for methodology development. PR was responsible for validation and testing. DS and GP were responsible for writing the first draft of the article. AU and PR were responsible for the revision and editing of the article.

\section{Disclosure statement}

We do not have any competing financial, professional, or personal interests from other parties.

\section{References}

Afful-Dadzie, E., Oplatkova, Z. K., \& Prieto, L. A. B. (2017). Comparative state-of-the-art survey of classical fuzzy set and intuitionistic fuzzy sets in multi-criteria decision making. International Journal of Fuzzy Systems, 19(3), 726-738. https://doi.org/10.1007/s40815-016-0204-y

Attri, R., \& Grover, S. (2015). Application of preference selection index method for decision making over the design stage of production system life cycle. Journal of King Saud University-Engineering Sciences, 27(2), 207-216. https://doi.org/10.1016/j.jksues.2013.06.003

Bagočius, V., Zavadskas, E. K., \& Turskis, Z. (2014). Multi-person selection of the best wind turbine based on the multi-criteria integrated additive-multiplicative utility function. Journal of Civil Engineering and Management, 20(4), 590-599. https://doi.org/10.3846/13923730.2014.932836

Ballou, R. H. (1997). Business logistics: Importance and some research opportunities. Gestão \& Produção, 4(2), 117-129. https://doi.org/10.1590/S0104-530X1997000200001

Biswas, T. K., Stević, Ž., Chatterjee, P., \& Yazdani, M. (2019). An integrated methodology for evaluation of electric vehicles under sustainable automotive environment. In P. Chatterjee, M. Yazdani, S. Chakraborty, D. Panchal, \& S. Bhattacharyya (Eds.), Advanced multi-criteria decision making for addressing complex sustainability issues (pp. 41-62). IGI Global.

https://doi.org/10.4018/978-1-5225-8579-4.ch003

Borujeni, M. P., \& Gitinavard, H. (2017). Evaluating the sustainable mining contractor selection problems: An imprecise last aggregation preference selection index method. Journal of Sustainable Mining, 16(4), 207-218. https://doi.org/10.1016/j.jsm.2017.12.006

Brans, J. P., \& Vincke, P. (1985). Note - A preference ranking organisation method: (The PROMETHEE method for multiple criteria decision-making). Management Science, 31(6), 647-656.

https://doi.org/10.1287/mnsc.31.6.647

Chauhan, R., Singh, T., Thakur, N. S., \& Patnaik, A. (2016). Optimization of parameters in solar thermal collector provided with impinging air jets based upon preference selection index method. Renewable Energy, 99, 118-126. https://doi.org/10.1016/j.renene.2016.06.046

Christopher, M. (2012). Logistics and supply chain management. Pearson.

Churchman, C. W., \& Ackoff, R. L. (1954). An approximate measure of value. Journal of the Operations Research Society of America, 2(2), 172-187. https://doi.org/10.1287/opre.2.2.172

Đalić, I., Stević, Ž., Karamasa, C., \& Puška, A. (2020). A novel integrated fuzzy PIPRECIA - interval rough SAW model: Green supplier selection. Decision Making: Applications in Management and Engineering, 3(1), 126-145. https://doi.org/10.31181/dmame2003114d

Erceg, Ž., Starčević, V., Pamučar, D., Mitrović, G., Stević, Ž., \& Žikić, S. (2019). A new model for stock management in order to rationalize costs: ABC-FUCOM-interval rough CoCoSo model. Symmetry, 11(12), 1527. https://doi.org/10.3390/sym11121527 
Erdogan, S. A., Šaparauskas, J., \& Turskis, Z. (2017). Decision making in construction management: AHP and expert choice approach. Procedia Engineering, 172, 270-276. https://doi.org/10.1016/j.proeng.2017.02.111

He, T., Ho, W., Lee Ka Man, C., \& Xu, X. (2012). A fuzzy AHP based integer linear programming model for the multi-criteria transshipment problem. The International Journal of Logistics Management, 23(1), 159-179. https://doi.org/10.1108/09574091211226975

Herrera-Viedma, E., Herrera, F., Chiclana, F., \& Luque, M. (2004). Some issues on consistency of fuzzy preference relations. European Journal of Operational Research, 154(1), 98-109. https://doi.org/10.1016/S0377-2217(02)00725-7

Hwang, C. L., \& Yoon, K. (1981). Methods for multiple attribute decision making. In Lecture Notes in Economics and Mathematical Systems: Vol. 186. Multiple attribute decision making (pp. 58-191). Springer. https://doi.org/10.1007/978-3-642-48318-9_3

Ilgin, M. A., Gupta, S. M., \& Battaïa, O. (2015). Use of MCDM techniques in environmentally conscious manufacturing and product recovery: State of the art. Journal of Manufacturing Systems, 37, 746-758. https://doi.org/10.1016/j.jmsy.2015.04.010

Jaukovic Jocic, K., Jocic, G., Karabasevic, D., Popovic, G., Stanujkic, D., Zavadskas, E. K., \& Thanh Nguyen, P. (2020). A novel integrated PIPRECIA-interval-valued triangular fuzzy ARAS model: E-Learning course selection. Symmetry, 12(6), 928. https://doi.org/10.3390/sym12060928

Kabir, G. (2015). Selection of hazardous industrial waste transportation company using extended VIKOR method under fuzzy environment. International Journal of Data Analysis Techniques and Strategies, 7(1), 40-58. https://doi.org/10.1504/IJDATS.2015.067700

Karabašević, D., Stanujkic, D., Maksimovic, M., Popovic, G., \& Momcilovic, O. (2019). An approach to evaluating the quality of websites based on the weighted sum preferred levels of performances method. Acta Polytechnica Hungarica, 16(5), 195-215. https://doi.org/10.12700/APH.16.5.2019.5.11

Karaşan, A., \& Bolturk, E. (2019, August). Solid waste disposal site selection by using neutrosophic combined compromise solution method. In 2019 Conference of the International Fuzzy Systems Association and the European Society for Fuzzy Logic and Technology (EUSFLAT 2019). Atlantis Press. https://doi.org/10.2991/eusflat-19.2019.58

Keršuliene, V., Zavadskas, E. K., \& Turskis, Z. (2010). Selection of rational dispute resolution method by applying new Step-wise Weight Assessment Ratio Analysis (SWARA). Journal of Business Economics and Management, 11(2), 243-258. https://doi.org/10.3846/jbem.2010.12

Keshavarz-Ghorabaee, M., Amiri, M., Zavadskas, E. K., Turskis, Z., \& Antucheviciene, J. (2018). An extended step-wise weight assessment ratio analysis with symmetric interval type-2 fuzzy sets for determining the subjective weights of criteria in multi-criteria decision-making problems. Symmetry, 10(4), 91. https://doi.org/10.3390/sym10040091

Kulak, O., \& Kahraman, C. (2005). Fuzzy multi-attribute selection among transportation companies using axiomatic design and analytic hierarchy process. Information Sciences, 170(2-4), 191-210. https://doi.org/10.1016/j.ins.2004.02.021

Kundu, P., Kar, S., \& Maiti, M. (2014). A fuzzy MCDM method and an application to solid transportation problem with mode preference. Soft Computing, 18(9), 1853-1864.

https://doi.org/10.1007/s00500-013-1161-0

Liao, H., Xu, Z., Herrera-Viedma, E., \& Herrera, F. (2018). Hesitant fuzzy linguistic term set and its application in decision making: A state-of-the-art survey. International Journal of Fuzzy Systems, 20(7), 2084-2110. https://doi.org/10.1007/s40815-017-0432-9

Maniya, K. D., \& Bhatt, M. G. (2011). The selection of flexible manufacturing system using preference selection index method. International Journal of Industrial and Systems Engineering, 9(3), 330-349. https://doi.org/10.1504/IJISE.2011.0431422 
Maniya, K., \& Bhatt, M. G. (2010). A selection of material using a novel type decision-making method: Preference selection index method. Materials \& Design, 31(4), 1785-1789.

https://doi.org/10.1016/j.matdes.2009.11.020

Mohagheghi, V., Mousavi, S. M., \& Siadat, A. (2016, December). Assessing E-waste recycling programs by developing preference selection index under interval type-2 fuzzy uncertainty. In 2016 IEEE International Conference on Industrial Engineering and Engineering Management (IEEM) (pp. 1259-1263). IEEE. https://doi.org/10.1109/IEEM.2016.7798080

Mota, B., Gomes, M. I., Carvalho, A., \& Barbosa-Povoa, A. P. (2015). Towards supply chain sustainability: Economic, environmental and social design and planning. Journal of Cleaner Production, 105, 14-27. https://doi.org/10.1016/j.jclepro.2014.07.052

Opricovic, S. (1998). Multicriteria optimization of civil engineering systems. Belgrade: Faculty of Civil Engineering.

Paul, M., Sridharan, R., \& Ramanan, T. R. (2016). A multi-objective decision-making framework using preference selection index for assembly job shop scheduling problem. International Journal of Management Concepts and Philosophy, 9(4), 362-387. https://doi.org/10.1504/IJMCP.2016.079843

Peng, X., Zhang, X., \& Luo, Z. (2019). Pythagorean fuzzy MCDM method based on CoCoSo and CRITIC with score function for 5G industry evaluation. Artificial Intelligence Review, 53, 3813-3847. https://doi.org/10.1007/s10462-019-09780-x

Popović, G., Milovanovic, G., \& Stanujkic, D. (2018). Prioritization of strategies for tourism development by applying a SWOT-SWARA analysis: The case of Sokobanja Spa. Teme - Časopis za Društvene Nauke, 42(3), 999-1016. https://doi.org/10.22190/TEME1803999P

Popović, G., Stanujkic, D., Karabasevic, D., Maksimovic, M., \& Sava, C. (2019). Multiple criteria approach in the ranking of the sustainable indicators for cultural heritage sites. Quaestus, 14, 165-175. https://www.quaestus.ro/en/wp-content/uploads/2012/02/popovic-stanujkic-karabasevic.pdf

Razavi Hajiagha, S. H., Mahdiraji, H. A., Hashemi, S. S., \& Turskis, Z. (2015). Determining weights of fuzzy attributes for multi-attribute decision-making problems based on consensus of expert opinions. Technological and Economic Development of Economy, 21(5), 738-755.

https://doi.org/10.3846/20294913.2015.1058301

Roy, B. (1991). The outranking approach and the foundation of ELECTRE methods. Theory and Decision, 31(1), 49-73. https://doi.org/10.1007/BF00134132

Saaty, T. L. (1980). The analytic hierarchy process: Planning, priority setting, resource allocation. McGrawHill.

Samanta, S., \& Jana, D. K. (2019). A multi-item transportation problem with mode of transportation preference by MCDM method in interval type-2 fuzzy environment. Neural Computing and Applications, 31(2), 605-617. https://doi.org/10.1007/s00521-017-3093-6

Sandberg, E. (2013). Understanding logistics-based competition in retail - a business model approach. International Journal of Retail \& Distribution Management, 41(3), 176-188. https://doi.org/10.1108/09590551311306237

Sawant, V. B., Mohite, S. S., \& Patil, R. (2011). A decision-making methodology for automated guided vehicle selection problem using a preference selection index method. In K. Shah, V. R. Lakshmi Gorty, \& A. Phirke (Eds.), Communications in Computer and Information Science: Vol. 145. Technology systems and management (pp. 176-181). Springer.

https://doi.org/10.1007/978-3-642-20209-4_24

Stanujkic, D. (2015). Extension of the ARAS method for decision-making problems with intervalvalued triangular fuzzy numbers. Informatica, 26(2), 335-355.

https://doi.org/10.15388/Informatica.2015.51

Stanujkic, D., Karabasevic, D., \& Cipriana, S. A. V. A. (2018). An application of the PIPRECIA and WS PLP methods for evaluating website quality in hotel industry. Quaestus, 12, 190-198. 
Stanujkic, D., Karabasevic, D., Zavadskas, E. K., Smarandache, F., \& Cavallaro, F. (2019). An approach to determining customer satisfaction in traditional Serbian restaurants. Entrepreneurship and Sustainability Issues, 6(3), 1127-1138. https://doi.org/10.9770/jesi.2019.6.3(5)

Stanujkic, D., Zavadskas, E. K., Karabasevic, D., Smarandache, F., \& Turskis, Z. (2017a). The use of the pivot pairwise relative criteria importance assessment method for determining the weights of criteria. Romanian Journal of Economic Forecasting, 20(4), 116-133. https://www.researchgate. net/publication/322940549_The_use_of_the_pivot_pairwise_relative_criteria_importance_assessment_method_for_determining_the_weights_of_criteria

Stanujkic, D., Zavadskas, E. K., Karabasevic, D., Turskis, Z., \& Keršulienè, V. (2017b). New group decision-making ARCAS approach based on the integration of the SWARA and the ARAS methods adapted for negotiations. Journal of Business Economics and Management, 18(4), 599-618. https://doi.org/10.3846/16111699.2017.1327455

Stević, Ž., Stjepanović, Ž., Božičković, Z., Das, D., \& Stanujkić, D. (2018). Assessment of conditions for implementing information technology in a warehouse system: A novel fuzzy PIPRECIA method. Symmetry, 10(11), 586. https://doi.org/10.3390/sym10110586

Tokar, T. (2010). Behavioural research in logistics and supply chain management. The International Journal of Logistics Management, 21(1), 89-103. https://doi.org/10.1108/09574091011042197

Torkayesh, A. E., Pamucar, D., Ecer, F., \& Chatterjee, P. (2021). An integrated BWM-LBWA-CoCoSo framework for evaluation of healthcare sectors in Eastern Europe. Socio-Economic Planning Sciences, 1-12. https://doi.org/10.1016/j.seps.2021.101052

Turskis, Z., Dzitac, S., Stankiuviene, A., \& Šukys, R. (2019a). A fuzzy group decision-making model for determining the most influential persons in the sustainable prevention of accidents in the construction SMEs. International Journal of Computers Communications \& Control, 14(1), 90-106. https://doi.org/10.15837/ijccc.2019.1.3364

Turskis, Z., Goranin, N., Nurusheva, A., \& Boranbayev, S. (2019b). Information security risk assessment in critical infrastructure: A hybrid MCDM approach. Informatica, 30(1), 187-211. https://doi.org/10.15388/Informatica.2019.203

Turskis, Z., Lazauskas, M., \& Zavadskas, E. K. (2012). Fuzzy multiple criteria assessment of construction site alternatives for non-hazardous waste incineration plant in Vilnius city, applying ARAS-F and AHP methods. Journal of Environmental Engineering and Landscape Management, 20(2), 110-120. https://doi.org/10.3846/16486897.2011.645827

Ulutaş, A., Topal, A., \& Bakhat, R. (2019). An application of fuzzy integrated model in green supplier selection. Mathematical Problems in Engineering, 2019, 4256359. https://doi.org/10.1155/2019/4256359

Vahdani, B., Mousavi, S. M., \& Ebrahimnejad, S. (2014). Soft computing-based preference selection index method for human resource management. Journal of Intelligent \& Fuzzy Systems, 26(1), 393403. https://doi.org/10.3233/IFS-120748

Wang, T. C., \& Chen, Y. H. (2008). Applying fuzzy linguistic preference relations to the improvement of consistency of fuzzy AHP. Information Sciences, 178(19), 3755-3765.

https://doi.org/10.1016/j.ins.2008.05.028

Wang, T. C., \& Chen, Y. H. (2011). Fuzzy multi-criteria selection among transportation companies with fuzzy linguistic preference relations. Expert Systems with Applications, 38(9), 11884-11890. https://doi.org/10.1016/j.eswa.2011.03.080

Wen, Z., Liao, H., Mardani, A., \& Al-Barakati, A. (2019a, August). A hesitant fuzzy linguistic combined compromise solution method for multiple criteria decision making. In J. Xu, S. Ahmed, F. Cooke, \& G. Duca (Eds.), Advances in intelligent systems and computing: Vol. 1001. Proceedings of the Thirteenth International Conference on Management Science and Engineering Management (pp. 813-821). Springer. https://doi.org/10.1007/978-3-030-21248-3_61 
Wen, Z., Liao, H., Ren, R., Bai, C., Zavadskas, E. K., Antucheviciene, J., \& Al-Barakati, A. (2019b). Cold chain logistics management of medicine with an integrated multi-criteria decision-making method. International Journal of Environmental Research and Public Health, 16(23), 4843. https://doi.org/10.3390/ijerph16234843

Wen, Z., Liao, H., Zavadskas, E. K., \& Al-Barakati, A. (2019c). Selection third-party logistics service providers in supply chain finance by a hesitant fuzzy linguistic combined compromise solution method. Economic Research-Ekonomska istraživanja, 32(1), 4033-4058. https://doi.org/10.1080/1331677X.2019.1678502

Yazdani, M., Wen, Z., Liao, H., Banaitis, A., \& Turskis, Z. (2019). A grey combined compromise solution (CoCoSo-G) method for supplier selection in construction management. Journal of Civil Engineering and Management, 25(8), 858-874. https://doi.org/10.3846/jcem.2019.11309

Yazdani, M., Zarate, P., Kazimieras Zavadskas, E., \& Turskis, Z. (2018). A Combined Compromise Solution (CoCoSo) method for multi-criteria decision-making problems. Management Decision, 57(9), 2501-2519. https://doi.org/10.1108/MD-05-2017-0458

Zavadskas, E. K., Antucheviciene, J., Adeli, H., \& Turskis, Z. (2016). Hybrid multiple criteria decision making methods: A review of applications in engineering. Scientia Iranica, 23(1), 1-20. https://doi.org/10.24200/sci.2016.2093

Zavadskas, E. K., \& Podvezko, V. (2016). Integrated determination of objective criteria weights in MCDM. International Journal of Information Technology \& Decision Making, 15(02), 267-283. https://doi.org/10.1142/S0219622016500036

Zavadskas, E. K., Turskis, Z., \& Kildienė, S. (2014). State of art surveys of overviews on MCDM/MADM methods. Technological and Economic Development of Economy, 20(1), 165-179. https://doi.org/10.3846/20294913.2014.892037

Zemlickiene, V., \& Turskis, Z. (2020). Evaluation of the expediency of technology commercialization: A case of information technology and biotechnology. Technological and Economic Development of Economy, 26(1), 271-289. https://doi.org/10.3846/tede.2020.11918

Zheng, J. H. (2015). A fuzzy TOPSIS approach based to evaluate the transportation mode selection: An experience in a suburban university. Advances in Transportation Studies, 1, 23-34.

Zolfani, S. H., Chatterjee, P., \& Yazdani, M. (2019, May). A structured framework for sustainable supplier selection using a combined BWM-CoCoSo model. In International Scientific Conference in Business, Management and Economics Engineering (pp. 797-804). Vilnius, Lithuania. 